Portland State University

PDXScholar

$11-18-1975$

\title{
The Effects of Low, Moderate, and High Self- Disclosure on Electromyographic, Psychogalvanic, and Attitudinal Response
}

Jonathan I. Lange

Portland State University

Follow this and additional works at: https://pdxscholar.library.pdx.edu/open_access_etds

Part of the Speech and Rhetorical Studies Commons

Let us know how access to this document benefits you.

\section{Recommended Citation}

Lange, Jonathan I., "The Effects of Low, Moderate, and High Self-Disclosure on Electromyographic, Psychogalvanic, and Attitudinal Response" (1975). Dissertations and Theses. Paper 2500.

https://doi.org/10.15760/etd.2497

This Thesis is brought to you for free and open access. It has been accepted for inclusion in Dissertations and Theses by an authorized administrator of PDXScholar. Please contact us if we can make this document more accessible: pdxscholar@pdx.edu. 
AN ABSTPACT OF THE THESIS OF J̈cnathan I. 'Lange for the Master of Science in Speech Communication presented November 18, 1975.

Titie: The Effects of Low, Noderete, and High Selt-Disclosure on Electromyographic, Psychogalvanic; and Attitudinal Response.

AFPROVET BI MEMBERS OF THE THESIS COMMITTEE:

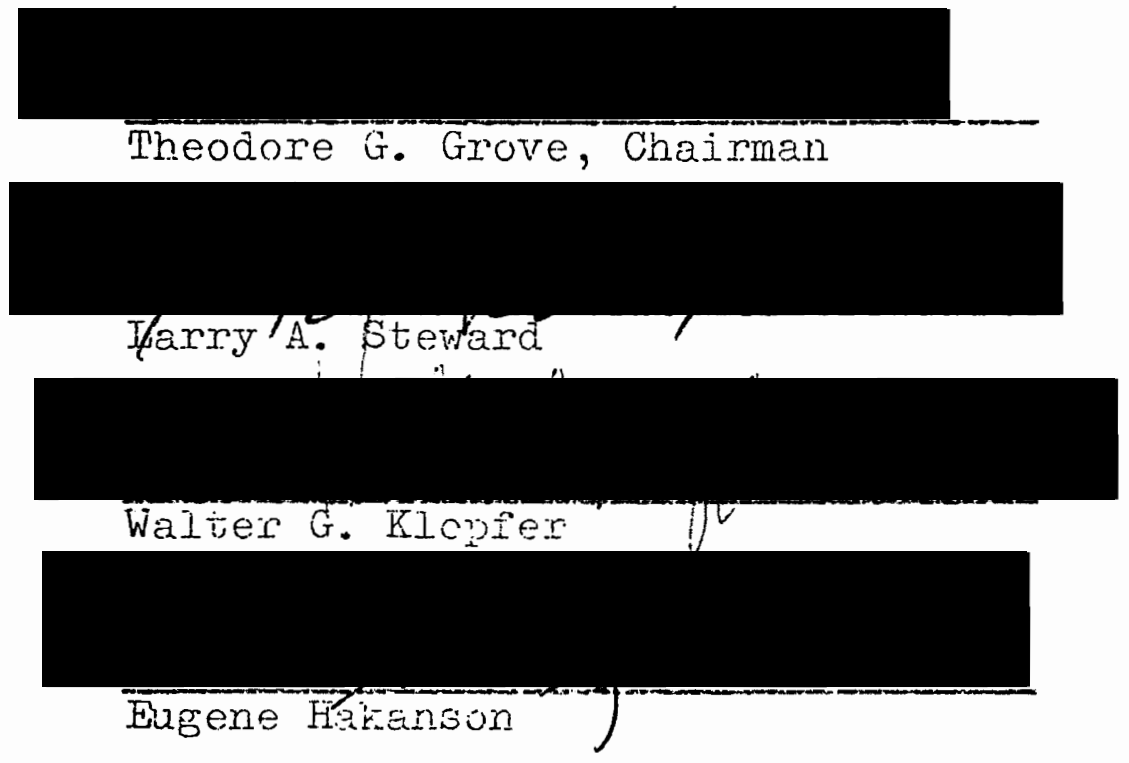

This is a study of the effects of three different levels of intimate seli-aisclosure, jow, wodente, and high, on electromyographic, peychogalvenic, and attitudinal response. The electromgograph (FMG) and psychogejvarometer (GSR) are both devices which measure physioiogical "actiration" or excitatior level of the indivioura. 
A review of the literature on selin...isclosure showed that few investigations dealt with the effects of disclosure. In order to test physiological and attitudinal response, 24 subjects, selected from various Speech Communication 100 courses, were, individually, connected to the Erig and GSR. Each subject was introduced to three opposite-sexed confederates, one at a time, who discilosed, for 1 minute, either low intimate, moderately intimate, or highly intimate information on one of two topics. After all three confederates were dismissed, the experjmenter obtained a rank order of preference, or, an attitudinal response by asking the subjects which stranger (confederate) would they prefer to meet with again. A second and third choice was also obtaineà.

Hence, the following three hypotheses were tested:

Hypothesis I. Change of electromyographic response will be a linear function of the increasing intimacy of the disclosures. That is, the higher the level of disclosure, the greater the electromyographic response.

Hypothesis 2. Change of psychogalvanic response will be a linear function of the increasing intimacy of the disclosures. That is, the higher the level of disclosure, the greater the psychogalvonic response.

Hyrothesis 3. Attitudinal response will be curvilinear. That is, subjects will choose to continue 
interaction with the moderate discloser more often than they choose to continue with either the high or low discloser.

Statistical procedures confirmed all three hypotheses, with disclosure order, sex, and topic making no significant difference. These results indicate that while activation is pleasant at particular points of intensity, too much or too little will cause a person to "withdraw" from the stimulus-in this case, the high- or low-disclosing confederate. To the extent that they are generalizable, the results also indicate that in an initial heterosexual encounter, moderate disclosure will best facilitate continued interaction. 
THE EFFECTS OF IOW, NODERATS, AND HIGH SELFDISCLOSURE ON ELECTROMYOGRAPHIC, PSYCHOGALVANIC, AND ATTITUIINAL RESPONSE

$$
\text { by }
$$

JONATHAN I. LANGE

A thesis submitted in partial fulfillment of the requirements for the degree of

MASTER OF SCIENCE in SPEECH COMMUNICATION

Portland Stä̌te University 1975 
TO THE OFFICE OF GRADUATE STUUDIES:

The members of the Committee approve the thesis of Jonathan I. Lange presented November 18, 1975.

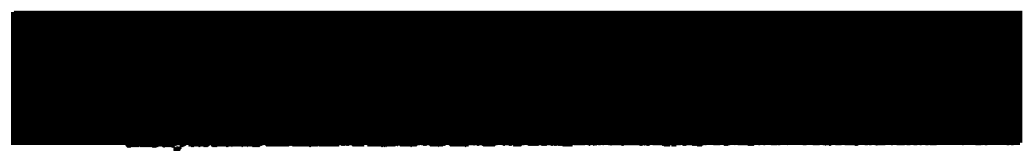

Theodore G. Grove," Chairman

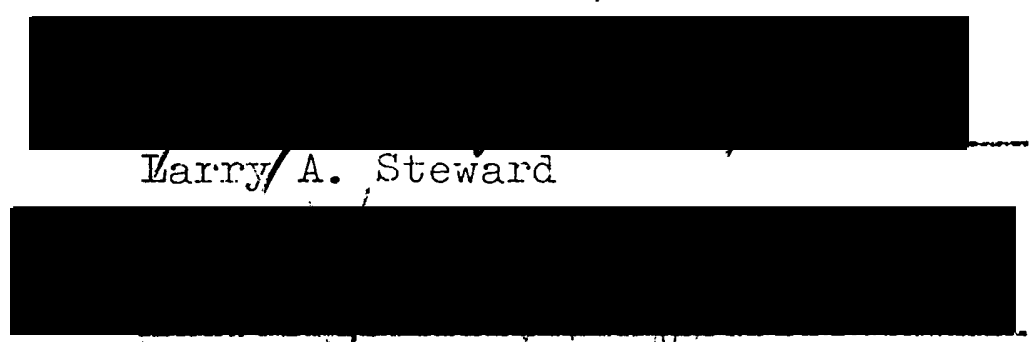

Walter G. Klopfer fl

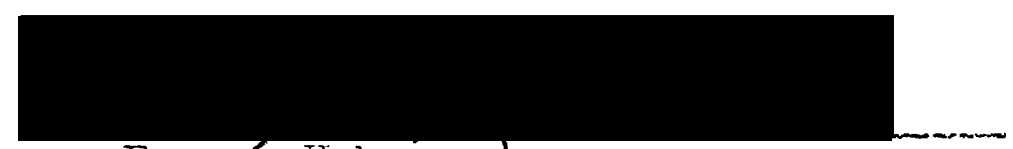

Eugené Hakansol

APPROVED:

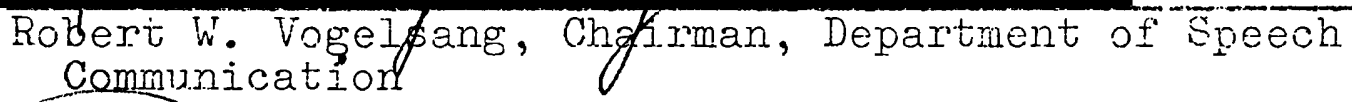

Pichara B. Halley, Actinz Dean of Graauate Studies anả
Research

November 26, 1975 


\section{ACKNOWLEDGMENTS}

The completion of this thesis would not have been possible without the cooperation of the stuff of the Department of Speech Communication, its Chairman, Dr. Robert W. Vogelsang, and many other persons. I would also like to acknowledge Professor LaRay M. Barna for her expert advice and assistance, as well as Dr. Robert E. Rinehart and Dr. Richard Burke for their technical assistance.

I particularly appreciated the patient, hard-working, and brave people who acted as my confederates: Chris, Jan, Leah, Mark, Paul, and Scott.

I. would like to acknowledge committee members Dr. Larry A. Steward, Dr. Walter G. Klopfer, and Dr. Eugene Hakanson for their constructive comments and criticism.

And above all, I appreciated, and benefited from, the contributions, encouragement, and support of my advisor, chairman, and friend, Dr. Theodore G. Grove. 
TABLE OF CONTENTS

PAGE

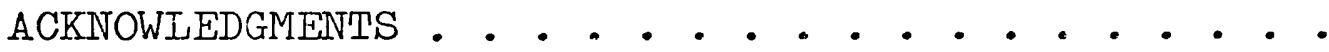

LIST OF TABLES . • • . . • . . . • • • •

LIST OF FIGURES . • . • • • . . • • . . . .

CHAPTER

I INTRODUCTION . . . . . . . . . . .

Tension-Anxiety . . . . . . •

Self-Disclosure: A Review of the

Literature . . . . . . . .

Measurement

Self-Disclosure and Mental Health

Personality Correlates of Self-Disclosure

Self-Disclosure Over Time

Reciprocity of Self-Disclosure

Iriking and Self-Disclosure

Sex, Race, and Cultural Differences

Disclosure in Therapy

Self-Disclosure and other

Summary Variables

II METHODS AND PROCEDURES . . . . . . . 20

Hypotheses . . . . . . . . 20

Design of the Study . . . . . . 21

Selection of Topics and

Stimulus statements 
Training of Confederates and

Development of Stimulus

Máterial

Subjects

Apparatus

Procedures

III RESUITS • . • . • • • • • • • • •

Electromyographic Response . • • •

Psychogalvanic Response . . . . • 36

Attitudinal Response . . . . . . 40

Additional Data Analysis ....... 41

IV DISCUSSION • • • • • • • • • • • •

Limitations of the Study

Suggestions for Future

Research

Summary

REFERENCES CITED

APPENDIX

A Release Statement . . . . . . • •

B Subject Ranking of Confederates . . • • 


\section{LIST OF TABLES}

TABLE

PAGE

I Stimulus Statements with Corresponding

Q-Scores and Intimacy Scale Values . .

II Preamplifier Specifications . . . . . . .

III Summary of Analysis of Variance of EMG . .

IV Orthogonal Comparison of Total FMG

Scores . . . . . . . . . . . .

$V$ Trend Analysis for EMG . . . . . . . . 36

VI Summary of Analysis of Variance for GSR . . 38,

VII Orthogonal Comparison of Total GSR

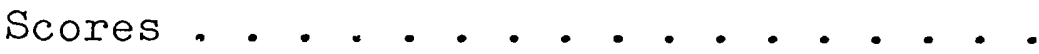

VIII Trend Analysis for GSR . . . . . . . • •

IX Summary of Wilcoxson T Ranking Totals . . 


\section{LIST OF FIGURES}

FIGURE

PAGE

I Sequential Illustration of Physiological

Treatment Groups . . . . . . .

22

2 Topic and Sex Balanced Against Disclosure

Variable . . . . . . . . . . 
CHAPTER I

\section{INTRODUCTION}

In 3.956, Sidney J. Jourard adopted the term selfdisclosure to describe "the act of revealing personal information to others" (Jourard 1971). A review of the literature on self-àisclosure shows that since 1958, there have been wel]. over one hundred articles and books published that deal directly with disclosing personal information to others. There are a variety of reasons for such high interest. We make ourselves known to others through selfdisclosure. It comprises the majority of talk in therapeutic encountiers. On the basis of such personal information people evaluate and make decisions about us (Mead 1934).

Special concern with disclosure to the opposite sex upon first meeting has been demonstrated not only in the various mass media, but by the increasing publication of books that speak directly to this issue (i.e., Bach \& Deutsch 1970, Bernard 1968, Fast 1971, Phillips \& Metzger 1976). It seems that the nature of ongoing interpersonal relationships is often significantiy affected by the events that transpire within the first 5 minutes of the relationship (Berscheid \& Walster 1969, Phillips 1973). Depending on his or her goals for the relationship, a speaker might reveal the wrong kind 
or amount of information upon first encountering someone of the opposite sex.

There have also been an increasing number of publjications in which authors prescribe, as ways for more effective living, beirg "real," "genuine," "congruent." We should "get behind the masks," quit "imaging" ourselves, drop the phony social roles that prevent us from being our "true selves" (e.g., Rogers 1961, Jourard 1971, Bach \& Deutsch 1970).

Kogers (1961) talks about being genuine:

This means that I need to be aware of my own feelings, in so far as possible, rather than presenting an out-ward facade of one attitude, while actually holding another attitude at a deeper or unconscious level. Being genuine also involves the willingness to be and to express, in my words and my behavior, the various feelings and attitudes which exist in me. It is only in this way that the relationship can have reality. . ( .33$)$

Bach and Deutsch (1970), in their advice to people seeking intimacy with the opposite sex, extrapolate from Rogers and conclude one of their chapters on initial encounters by saying that "anyone who can be open and genuine can approach anyone else with a probability of some success" (p. 137).

However, this kind of advice can be easily misconstrued and might be too strong. For example, if, in an. initial encounter, one discloses very personal information, the recipient of that disclosure might perceive the discloser as untrustworthy and/or lacking in discretion. It seems 
that being "open and genuine" should have limits. Thibaut and Kelly (1959) wisely described the formaljty and constraint which lisually characterize first encounters as functioning to prevent the forming of relationships which may prove unsatisfying in the future.

Concerned, in part, with this issue, Cozby (1972) confronted subjects with disclosures from hypothetical. others, the disclosure statements varying in intimacy level-high, moderate, and low. He predicted that (a) the relationship between liking and disclosure would be curvilinear, and (b) the relationship between reciprocity and djsclosure would be curvilinear. Subjects would like the moderate-disclosing person best and would return more disclosures to the moderatedisclosing person as well. The high discloser would arouse "anxiety" with his overly intimate disclosure and thus be seen as providing the subject with negative outcomes, whereas the low discloser would be perceived as boring, uninteresting-not one to like or disclose a lot to. The liking hypothesis was verified'but subjects reciprocated disclosure in a linear fashion.

Verification of the liking hypothesis has important, implications for interpersonal relationsilip satisfaction. If one's interpersonal goals includes being liked by those he encounters, then maybe one should initially disclose information of moderate intimacy value. It would seem that those who engage in only very high or very low level intimate 
disclosure on first meeting will have difficulty in forming new, ongoing relationships.

Cozby's investigation is among the few that deal directly with the effects of self-disclosure from another. Other investigators have stuäied reciprocity and liking and will be discussed in the review of the literature. Three more investigations should now be noted.

Benedict (1971) investigated the effects of selfdisclosure on the development of trust. She used confederates and varied the intimacy levels of their disclosure to subjects in four different conditions: (1) high, then low, (2) low, then high, (3) high only, and finally (4) low. In all conditions except the fourth, in which low disclosure only was employed, subjects did not trust the confederate, and saw him as "eccentric, socially inept, and less well adjusted" than the low-disclosing confederates (p. 71).

Gilbert (1973), predicting that high disclosure would produce greater attraction and perceived trust than low disclosure, found the opposite to be true for her subjects. She used two conditions, high- and low-disclosure.

Jones and Gordon (19'72) asked their subjects to view video-taped interviews and evaluate the appropriateness of disclosure of good or bad fortune early in a relationship. Findings supported the notion that it is unattractive to disclose good fortune early in the relationship, and if the discloser was not responsible for a negative experience (bad 
fortune) he was less liked if he disclosed this information early, rather thar late in the interview.

These investigations provide data that seem to suggest that disclosure of hj.ghly personal information early in a relationship violates social expectations and is deemed inappropriate. Yet the Jones and Gordon investigation was concerned only with the disclosure of good or bad fortune. The Benedict and Gilbert studies included no condition with a moderate amount of disclosure. And the Cozby (1972) study had deficiencies as well. One drawback wəs his use of hypothetical, as opposed to real, others. Another was that his investigation, like the others, did not include a possibility for future interactions between subjects. This, as he points' out in a later article, may have affected liking ratings and amount of disclosure reciprocated (Cozby 1973). This will be discussed more fully in the review of the literature.

The present study confronted subjects with "real" others and included a possibility of continued interaction between subjects in attempting to assess the effects of 1.ow, moderate, and high self-disclosure on electromyographic, psychogalvanic, and attitudinal response. The electromyograph (EMG) and psychogalvanometer (galvanic skin reflex or GSR) were employed in an attempt to measure tension and anxiety. 


\section{TENSION-ANXIETY}

Between 1950 and 1966 there were over 3,500 articles or books published related to anxiety (Spielberger 1966). Fublication continues and yet, there has been little or no agreement on the definitior of anxiety (Barna 1970).

Levitt (1967) says: "The range of possible definjtions is, in principle, unlimited, and in practice, very broad" (p. 7). His summarizing statement is that, roughly speaking, anxiety is "a complex state characterized by a subjective feeling of apprehension and heightened physiological reactivity" ( $\mathrm{p}, 6)$.

Similar problems occur in trying to ảefine "tension." After a survey of the literature, Levjtt (1957) concludes that:

Tension may refer either to a condition of the musculature of the body which indicates the presence of anxiety, or to a vague feeling of restlessness which suggests the presence of anxiety at a level below conscious awareness ( $p .16)$.

Barna (1970), in her review of the literature, goes so far as to say that, "The terms 'tension' and 'anxiety' are used. freely and interchangeably and have specific meanings to each person considexing them" (p. 35).

Measurement of tension-anxiety is also difficult. While introspective reports, observer rating-scales, and communication differences are sometimes employed, Barna (1970) points out that: 
- physiological measures are being used more and more frequently. Autonomic nervous system reactions can seldom be controlled voluntarily and are thus immune from denial, providing good operational definitions of "a state of anxiety." An example of this type of measurement device is the "Iie detector" which uses measurements of blood pressure, heart rate, respiration rate, and electrical skin resistance, or individual measures of each, particularly the Galvanic Skin fieflex (GSR). The electromyograph.. measures muscle tension . . (. ( 37 )

Yet, Duffy (1962) cautions against using physiological reactions as synonyms for psychological concepts (e.g., drives; motives, emotions). She invokes the term "activation" referring to "variations jn the excitation of the individual as a whole, as indicated roughly by any one of a number of physiological measures. . . The degree of activation appears to be best indicated by a combination of measures" (p. 3). She further states:

Opservation of behavior, as well as the analysis of current psychological concepts, suggests that there are only two basic respects in which behavior shows variation. These are direction and intensity. An organism may approach or withdraw from a stimuius situation, and this approach or witharawal may take place at any one of many possible degrees of intensity. (p. 5).

Finally, Barna (1970) points out, when using physiological reaction to measure anxiety as a psychological concept, cognitive factors must also be recognized. An evert or stimulus may be perceived as threatening, in which case the organism would probably withdraw--or exciting and challenging, a case in which we could expect the orgarism to approach the stimulus situation. Coupled with Duffy's 
analysis, this suggests that activation is pleasant to a point, after which the organism's withdrawal indicates the subjective feeling of apprehension that we call "anxiety."

Again, Barna (1970) provides the data from which to proceed in measuring activation or tension-anxiety. She warns to "accumulate as much information as possible through a variety of measurements and through consideration of the cultural and historical background of the individual plus the impinging factors of the momentary situation" (pp. 41 , 42). The present study employed the galvanic skin reflex (GSR) and the electromyograph (EMG) in measuring physiological reaction to the reception of low, moderate, and high self-disclosure and incorporated a measure of attitudinal response to distinguish between anxiety and activation. Consideration of the cultural background of individual subjects will be discussed in the next section.

\section{SEIF-DISCLOSURE: A REVIEW OF THE LITERATURE}

\section{Measurement}

The instrument most often used to assess individual differences in self-disclosure has been Jourard's SelfDisclosure Questionnaire (JSDQ). The initial instrument consisted of 60 items--10 items in each of six content areas: attitudes and opinions, tastes and interests, work or studies, money, personality, and body (Jourard 1958). In this instrument, subjects responded to each item by 
indicating the extent to which the information has been revealed to four target persons: mother, father, best opposite-sex friend, and best same-sexed friend. Items are scored as 0--no disclosure to the target person, 1--disclosure only in general terms, or 2--full and complete disciosure about the item in question. Jourard (1971) later developed a shorter version of the instrument, scored the same way, but with 25 items.

Cozby (1973), in reviewing the literature on selfdisclosure, found little evidence for the predictive validity of either form of the JSDQ. He points out that JSDQ scores reflect a subject's past history of disclosure to parents and persons who are labeled "best same-sex friend" and "best opposite-sex friend."

Cozby described several other measures of selfdisclosure, though they have not been widely used. Two versions (25 item and 50 item) of the Social Accessibility Scale were developed by Rickers-Ovsiankina (1956, 1958). The scale differs from the JSDQ in that (a) subjects are instructed to indicate what they would disclose rather than whet they have disclosed, and (b) the target persons are a stranger, an acquaintance, and a best friend. Vondracek and. Vordracek (1971) developed a system for scoring selfdisclosure by preadolescents. West and Zingle describe a Self-Disclosure Inventory for Adolescents (1969). 
Polansky (1965) used an incompiete sentence method in measuring "verbal accessibility." Finally, Taylor and Altman (1966) scaled 671 statements for intimacy value and topical category. The present investigation employs some of the statements developed by Taylor and Altman.

An important study by Hood and Back (19?1) demonstrated that subject volunteerism was a source of bias in the laboratory. Their investigation shows that volunteers for studies in disclosure actually disclose more than nonvolunteers. For this reason, the present study did not use volunteers.

\section{Self-disclosure and Mental_Health}

Jourard (1959) argued that the ability to allow one's real self to be known to at least one "signifj.cant" other is a prerequisite for a healthy personality. In The mransparent Self (1964), Jourard elaborated on the relationship between self-disclosure and mental health suggesting that the relationship between the two variables is curvilinear; that a certain amount of disclosure is healthy, but can go too far if done "indiscriminantly." Since then, a number of investigators have used various measures of mental health (including the Pederson Personality Inventory Cycloid Disposition Scale, the Marlowe-Crowne Social. Desirability Scale, various scales of the MMPI, a self-esteem index) in attempting to correlate self-disclosure with healthy personality. Cozby's (1973) 
review of these studies indicated that there were an almost equal number of investigations finding positive correlations as there were finding negative correlations or no correlation at ail. No correlation reported. was greater than. 50 , arid most were much lower.

Taking note of the conflicting results, Cozby refers back to the curvilinear relationship suggested by Jourard and offers the following explanation:

Persons with positive mental health (given that they can be identified) are characterized by high disclosure to a few significant others and medium disclosure to others in the social environment. Individuals who are poorly adjusted (again assuming a suitable identification can be made) are characterized by either high or low disclosure to virtually everyone in the social environment. Future research should help to clarify this rather confused aspect of selfdisclosure ( $\mathrm{p} .78)$.

\section{Personality Correlates of}

\section{Self-Disclosure}

Cozby (1973) also reviewed the literature involvirig correlations between self-äisclosure and various personality measures (Femininity, Authoritarianism, Sociability and. Extraversion, College Achievement, and Interpersonal Trust). Other than an apparent positive relationship between selfdisclosure and extraversion, the correlations were generally low, the results often contradictory.

So, though several personality characteristics

(includirg mental health) may be associated with selfdisclosure, few replications of results have been obtained. Altman and Taylor (1973) go so far as to state that it is 
unrealistic to expect to find specific trajt-disclosure relationships. They urge the study of personality and selfdisclosure within the context of specific interpersonal relationships and settings.

\section{Self-I)isclosure Over Time}

Social penetration theory places seli-disclosure within the context of exchange (Altman and Taylor 1973, Taylor, Altman, \& Sorrentine 1.969). In this theory, interpersonal relationships and disclosure are described as developing from nonintimate to intimate areas of exchange. Rate and amount of movement from nonintimate to intimate disclosure is determined by reward/cost factors of past, present, and projected future exchanges. While similar to social exchange theory (Homans 1961, Thibaut \& Kelly 1959), sociái penetration theory differs in that the time dimension is emphasized as a factor in exchange.

With the time factor in mind, Taylor (1968) administered a self-âisclosure questionnaire to male freshman roommates at time intervals of $1,3,6,9$, and 13 weeks. He found a rapid increase in nonintimate disclosures, and a gradual increase in intimate disclosures over time.

Jourard (1961) studied college students ranging in age from 17 to 55 years. It was found that disclosure to parents decreased with age, while disclosure to oppositesex friend or spouse increased up to age 40, after which a decrease was observed. 
Reciprocity of Seli-Disclosure

If, in interpersonal relationships, disclosures are exchanged over time, it seams probable that "disclosure begets disclosure," or, there is a reciprocity effect of self-disclosure. Jourard tested this idea on three separate occasions with nurses, and graduate students, and faculty members (Jourard 1959b, Jourard \& Landsman 1960, Jourard \& Richman 1963). In all three investigations, the amount disclosed to a given colleague correlated highly with the anount of disclosure receivea from that colleague. Further evidence for the reciprocity effect was found when Jourard and Richman (1963) correlated subject's reports of disclosure output and input (disclosure received) for the four target persons on the JSDQ.

Rivenbark (1971) reports high correlations between reported output and input for adolescents. Levinger and Senn (1967) found a reciprocity effect for husband's and wives' disclosure of feelings. However, Cozby (1973) points out that in the last three studies cited, correlations were probably artificially high due to the fact that output and input scores were received from the same person.

Enrlich and Graeven (1971) confronted subjects with confederates disclosing at high and low intimacy levels. Chittick and Himmelstein (1967) also used confederates but varied the number of statements disclosed. In both investigations the high-disclosing confederates elicited greater 
self-disclosure than the low-disclosing confederates, again affirming the reciprocity theory. Worthy, Gary, and Kahn (1969) and Certner (1973) verified the reciprocity effect iri sinal. groups.

Juevin and Gergen (1969) took another approach. Believing that a person revealing a freat deal about himself would be perceived as lacking discretion, they predicted a curvilinear relationship between other disclosure and subject disclosure. However, their hypothesis was not verified. When subjects received a 40-item seli-rating form from a partner on which either 4, 16 , or 32 items were checked, subjects reciprocated with mean totals of 10.5, 17.2, and 22.0 items in the low, moderate, and high groups respectively--a linear effect.

Cozby (1972) tried again. Previously mentioned was his investigation in which he predicted that reciprocity would determine subject's responses to a low-- and medium-disclosing hypothetical other, but that intimacy level would not increase, maybe even decrease, as other-disclosure increased from medium to high intimacy level. He argued that while increasing intimacy of disclosure may represent increasing reward, various costs come into effect at high intimacy levels, the nost obvious being anxiety over revealing information one would rather keep private. If disclosure begets disclosure, subjects may feel pressure to respond in kind to high disclosure. However, the results were like that of Ievin and 
Gergen. Subject disclosure increased in a linear fashion.

Cozby (1973), in a later article, concludes:

Reciprocity appears to become less powerful as a determinant of subjects' responses at high levels of intimacy, but there is as yet no explanation for the counterintuitive results cbtained by Levin and Gergen, and Cozby. It is possible that making selfdisclosures is rewarding for the person who is djsclosing, and the laboratory setting is a particularly likely place for this to occur. In other words, the reward effect may tend to outweigh the the anxiety discussed previously in a laboratory setting jn which subjects did not see each other, and there is little likelihood of future interactions... . It is possible that the curvilirear effect would be obtained in a situation in which there was a possibility of future interaction (p. 82).

The present study predicts a curvilinear effect and structures subjects' perceptions to include an immediate, additional interaction with one of three confederates. (See Chapter II.)

\section{Liking and Self-Disclosure}

Besides reciprocity, liking is a variable often found in self-disclosure studies. Jourard (1971) conducted, or co-conducted several experiments in which liking was correlated with self-disclosure. He consistently found high correlations for female subjects, but not for males. He attributed these results to the different role expectations society has of men and women, and says that the results also corroborate "statements abounding in popular literature which portray men as strong and silent and distrustfu]. of feelings; women are commonly portrayed as more emotional, talkative.." (p. 26). 
Cozby (1973) cites other investigations finding a relationship between liking and disclosure (Halverson \& Shore 1969, Fitzgerald 1963, Altman \& Haythorn 1965, Worthy et al. 1969). Yet Fhrlich and Graeven (1971) found no relationship in their study of all male subjects, seeming to verify iourard's findings. But Cozby (1973) points out why these results must be questioned. Al] studies, while varying intimacy value, did not account for subject response being affected by content of the different levels of disclosure. If a subject rated a high discloser as well liked, it could be because the subject agreed with what the discloser had to say, and not because of the high intimacy value of the disclosure. To avoid this trap, Cozby (1972) used a roleplaying procedure (hypothetical others) and found strong support for the aforementioned curvilinear effect. The present study employed two separate topics so as not to confound subject ratings of confederates with content.

\section{Sex, Race, and Cultural Differences}

In reviewing the literature, this author found an almost equal number of investigations that reported sex differences in'disclosure as did not. All investigations reporting sex differences, however, found females higher in disclosure output than males. This, as Cozby (1973) points out, may be indicative of actual sex differences in that no study yielded results in which males disclosed more. 
Jourard (1971) notes differences in disclosure output between Caucasians and Blacks, Amexicans and Puerto Ricans, British women and American wonen. In all cases, the Caucasian American disclosed more. Plog (1965) found evidence for the hypothesis that Americans disclose more than Germans. In light of these findings, the present study used Caucasian American subjects only.

\section{Disclosure in Therapy}

Jourard (1964, 1971) and Rogers (1961) are among the leading advocates of therapist disclosure and client (patient) disclosure in therapy. Truax and Carkhuff (1965) showed that level of patient disclosure could be a predictor of final case outcome and reported significant correlations between therapist and patient disclosure.

However, objections to therapist disclosure to jncrease patient disclosure have been raised by many. Polansky (1967) implies that the technique is clinically "sloppy."

It would seem that the efficacy of therapist disclosure would depend on the client and his reason for being there, the therapist and his preferred mode of treatment, and a host of intervening situational varjables.

\section{Self-Jisclosure and Other Variables}

Cozby (1973) in his review of the literature on selfdisclosure, lists a few additional studies which dealt with 
variables not yet mentioned. Social approval, dependency; and religion were found to have little or no effect on disclosure. However, Jourard and Friedman (1970) found that for females, as eye contact and physical distance increased: duration of disclosure increased. Dimond and Munz (1.967) found that later-borns show higher self-disclosure scores than firstborns.

\section{Summary}

While the greatest number of empirical investigations in the area of self-disclosure have attempted to correlate personality traits or mental health with either amount or intimacy level of disclosure, the results are confusing and often contradictory. Also unclear are the results of attempts to check for sex differences in disclosure. There does, however, seem to be definite cultural differences, with Caucasian Americans disclosing more than any other cultural group studied.

It appears that there is a reciprocity effect of disclosure. Amount and intimacy level of information disclosed correlates with the amount and intimacy level of information disclosed in returin. And while some studies have found a positive relationship between liking and djsciosure, results are questionable due to the confouriding variable of content. Other than these studies (reciprocity and liking), there have been few experiments investigating the effects of disclosure on others. 
As for disclosure in the psychotherapeutic interview, there is unilateral agreement as to the importance of patient or client disclosure. However, therapists of different theoretical persuasions do not agree on the question of therapist disclosure as a beneficial psychotherapeutic technique. 


\section{CHAPTER II}

\section{METHODS AND PROCEDURES}

The present investigation was designed to assess the effects of receiving, low ( $L$ ), moderate (M), and high ( $H$ ). self-disclosure on electromyographic, psychogalvanic, and attitudinal response.

\section{HYPOTHESES}

There were three hypotheses for this study:

Hypothesis 1. Change of electromyographic response will be a linear function of the increasing intimacy of the stimulus statement. That is, the higher the level of disclosure, the greater the electromyographic response. $(\mathrm{H}>\mathrm{M}>\mathrm{L})$

Hzpothesis 2. Change of psychogalvanic resporse will be a linear function of the increasing intimacy . of the stimulus statement. That is, the higher the level of disclosure, the greater the psychogalvanic response. ( $H>M>I)$

Hypothesis 3. Attitudinal response will be curvilinear. That is, subjects will choose to continue interaction with the medium discloser more 
often than they choose to continue with ejther the high or low discloser. $(H>M<L)$

\section{IJ. DESIGN OF THE STUDY}

In order to test electromyographic, psychogalvanic, and attitudinal response to different levels of disclosure from an opposite-sex stranger, a $2 \times 2$ × 3 repeated measures analysis of variance design was employed. The independent variable, self-disclosure, had three different levels:

low (I), moderate (M), and high (H). There were two control variables: sex and topic.

Each subject, after being connected to the EMG and the GSR met, one at a time, three opposite-sexed stranger: who were confederates of the experimenter. Each confederate disclosed something about himself for approximately 1 minute. All subjects received three different levels of disclosure (stimulus statements)--low, moderate, and high--each Jevel from a different confederate. Order of exposure to the three different levels of disclosure was balanced such that an equal number of subjects encountered any given levei in first, second, or third position (see Figure 1). Confederates aisclosed at low, moderate, and high level.s to an equal number of subjects.

Half of the 24 subjects were male, balf female. Two topic areas were used and varied such that half the males received stimulus statements from topic area number one, the 
other half receiving disclosures from topic area number two. The same conditions applied for the female subject population. Half received disclosures from topic area number one, the other half from topic area number two.

Thus, there were six conditions in which each condition had two male and two female subjects receiving a different order of disclosure level presentation. In this way, effects of order, topic, and sex could be tested for significance. A schematic drawing of the repeated measures design used for EMG and GSR is presented in Figures 3. and 2.

$\begin{array}{ll}\text { Condition 3.. } & \text { H M I } \\ \text { Condition 2. } & \text { H I M } \\ \text { Condition 3. } & \text { M H I } \\ \text { Condition 4. } & \text { M I H } \\ \text { Condition 5. } & \text { I H M } \\ \text { Condition 6. } & \text { I M H }\end{array}$

Figure 1. Sequential illustration of physiological treatment groups. (Attitudinal response or rank ordering of confederates not depicted.)

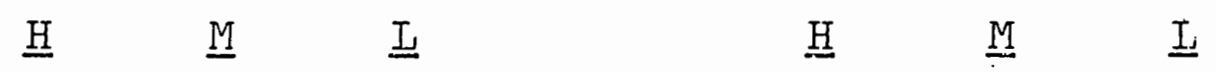

Topic $12 \mathrm{Ss} 12 \mathrm{Ss} 12 \mathrm{Ss}$ Male $12 \mathrm{Ss} 12 \mathrm{Ss} 12 \mathrm{Ss}$ Topic $212 \mathrm{Ss} 12 \mathrm{Ss} .12 \mathrm{Ss}$ Female $12 \mathrm{Ss} 12 \mathrm{Ss} 12 \mathrm{Ss}$ Figure 2. Topic and sex balanced against disclosure variable. 
Selection of Topics and

Stimulus statemerits

Two topical categories were required, each with three stimulus statements of high, moderate, and low intimacy value. In 1966, Dalmas Taylor and. Irwin Altman developed, categorized, and scaled 6?1 statements for use in research on interpersonal exchange and self-disclosure (Taylor \& Altman 1966). Their pool of statements, dealing with various topics about the self, was taken from existing personality and self-disclosure instruments. Next, each subject (college freshmen) rated half the total pool of items on an 11-point scale regarding the degree of intimacy or personal character of the information in each statement. Thurstone scale values (meaian judgments on the 11-point scale) and Q-values (inter-quartile ranges) were computed to yield intimacy-scaled scores. Of the original 50 Ss, 27 classified the intimacy-scaled statements into thirteen topical categories.

"Love-Dating-Sex" and "Emotions-Feelings" were both topics in which there was (a) high agreement among student judges as to the accuracy of topic placement, and (b) a wide range of intimacy-scale values within the category. These topics were selected for the present study.

The stimulus statements chosen, along with thejr intimacy scale value (SV) and corresponding Q-score, are listed in Table I. 


\section{TABLE I}

STIMULUS STATEMENTS WITH CORRESPONDING

Q-SCORES AND INTIMACY SCALE VALUES

\section{Love-Dating-Sex}

Level

Stimulus Statement

SV

Q

Low

My feelings about blind dates

3.46

2.95

Moderate

My views on sexual morality--

how I feel that $I$ and others

ought to behave in sexual

matters

$7.50 \quad 3.53$

High

Feelings about my adequacy in

sexual behavior--my ability to

perform adequately in sexual

relationships

$10.11 \quad 2.31$

Emotions-Feelings

Low Topics of conversation that

bore me

$3.27 \quad 3.27$

Moderate What annoys me most in people

$5.89 \quad 3.12$

High

Things in the past or pres-

ent that I feel ashamed or

guilty about

$10.25 \quad 1.34$

\section{Training of Confederates and}

Development of Stimulus

\section{Material.}

In order to convert the above stimulus statements into six disclosures, each approximately 1 minute in length, the experimenter met with the six confederates and by method of group consensus composed and developed the final stimulus 
The experimerter assigned each confederate the task of creating a l-minute monologue for each stimulus statement. The stimulus statements themselves served as topic senterces for the minute of aisclosure.

With the experimenter and confederates meeting as a group, consensus was achieved by having each confederate verbalize to the rest the aisclosure for each stimulus statement. If there was a group consensus that the disclosure was appropriate (not too high or too low for the level in question), then the confederate went on to the next stimulus statement and disclosure. If group consensus was not achieved, the confederate had to change his or her disclosure until the group was satisfied that the disclosure was at the appropriate level (high, moderate, or low). Group consensus was reachea only when the group voted unanimously that the disclosure was indeed appropriate for the desired level. Thus, by the end of the meeting, each confederate was prepared with six Iminute disclosures: a low, moderate, and high in each topical category.

\section{Subjects}

The subjects were students (predominantly freshmen) enrolled in Speech 100, "Basic Speech Communication" at Portland State University, Winter term, 1975. During the first week of class, the instructors of three class sections passed the following handout to all their students: 
As part of the requirements for this class you may be called upon to particjpate in a research project requiring no more than one hour of your time and scheduled at your convenience. The project focuses on matters of central concern to students of human communication.

Project credit will be given to those who are selected to participate. Upon selection, you will be informed about your part in the project and subsequently will receive a report on project results.

Fill in the times you are NOT AVAILABLE (NA) in the time blocks below:

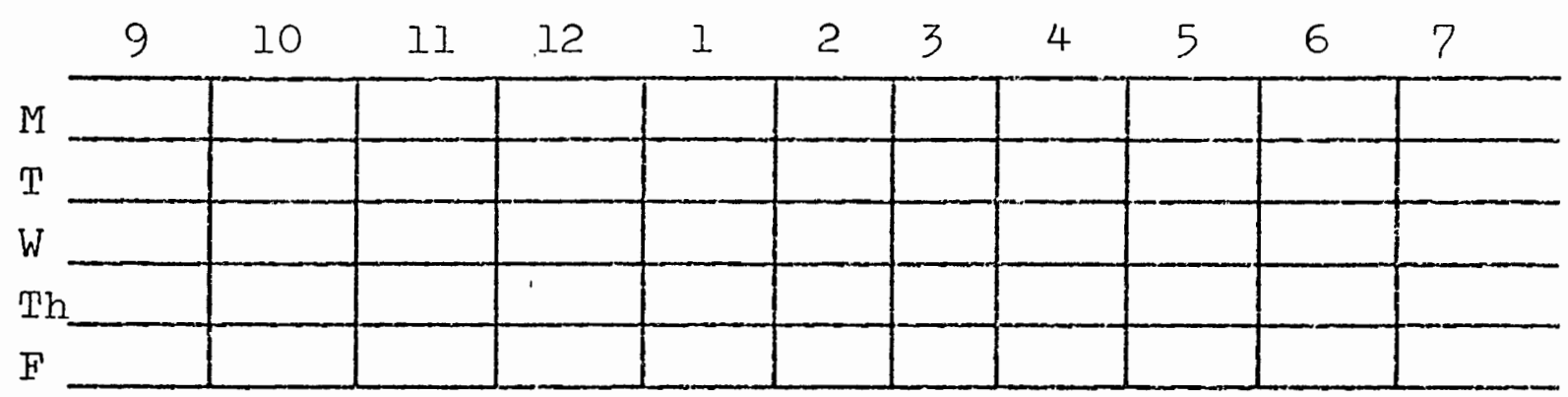

Subject selection was made accordjng to the following criteria and constraints:

I. All subjects chosen were native, Caucasian Americans. Jourard (1971) demonstrated cultural and raciel differences in self-disclosure norms. Therefore, information provided by the individual instructors screened out nonwhite and nonAmerican students.

2. Scheduling of the experiment required that male subjects report when all three female confederates were available. Female subjects fulfilled the same criterion with regard to male confederates. When twelve females and twelve males meeting the above requirements were obtained, subject selection ended. 
Students chosen were later given reminder slips with their name, time and date to report, room number of laboratory, and a request not to wear a high collared shirt or sweater. This was to facilitate easy placement of the EMG electrodes on the trapezius muscle.

Subjects were told nothing else prior to their reporting to the designated room. If they questioned their instructor as to the nature of the experiment, they were told that they would find everything out upon reporting.

\section{Apparatus}

A four-channel 105-125 V $60 \mathrm{~Hz}$ Projector Physiograph PMP-4A was used to record subject response. Paper speed was constant at 2 centimeters per second on rectilinear write-out coordinates.

The Time and Event Channel was set to give a downward deflection at the 60 second time mark. A GSR (Galvanic Skin Response) Preamplifier and an EMG (Electromyograph) HI-Gain Preamplifier were the other two channels used in this investigation. Their specifications follow. 
TABLE II

PREAMPLIFIER SPECIFICAIIONS

GSR

Maximum Sensitivity . . . . . $300 \mathrm{ohms} / \mathrm{cm}$ of pen deflection

Response Time......... . $30 \mathrm{~ms}$.

Time Constant .. . . . . . de coupled--infinite

Noise Level . . . . . . . Less than $0.01 \%$

Stability . . . . . . . . Less drift than

$\mathrm{lmm} / \mathrm{hr}$

Calibration . . . . . . . Internal +500,

+2500 , and +1.0,000

ohms resistance

changes

Warm-up Time .......... 10 minutes

Zero Suppression ...... I0 turn direct dial

(dc only)

Subject Resistance Range ..... 0-1,000,000 ohms

Input . . . . . . . . . . Single-ended

Applied Current . . . . . 20 microamperes de

EMG

Sensitivity . . . . . . Exceeds $30 \mathrm{mV} / \mathrm{cm}$ of pen deflection

Frequency Response ....... 0.05 to over 12,000 Hz Time Constant . . . . . . . . 3 seconds

Noise Level ... . . . . . Less than 5 microvolts

Voltage Gain (max) . . . . . Approx. 2500

Calibration .......... . . . . . millivolt

Warm-up Time ......... 5 minutes

Common Mode Rejection Ratio... Better than 10,000 to 1

Input Impedance . . . . . . . Differential, 6

Maximum Input Signal . . . . . 50 millivolts peakto-peak 
The two GSR electrodes were taped to the skin. EMG . electrodes were attached to suction cups so that attachment to the skin did not necessitate taping. An electrolyte paste was used as a conductor for the EMG electrodes.

\section{II.I. PROCEDURFS}

Upon arrival, each subject, was welcomed to the laboratory and led to the physiograph. The experimenter informally explained the nature and function of the machine by saying:

This is an electromyograph and a psychogalvanometer. They measure the electrical activity on the surface of the skin and muscles. NO ELECTRICITY COMES OUT OF THE MACHINE. THERE IS ABSOLUTELY NO POSSIBILITY OF ELECTRIC SHOCK.

I will hook you up to the machine and then you will meet three people of the opposite sex. They will read to you from this book [Arabian Nights, by Robert Iouis Stevenson] while I get a baseline reading, and then talk to you about themselves-something within the general category of

Half the subjects were told "emotions and feelings," the other half, "love, dating, and sex." The experimenter continued:

They have chosen what they want to talk about-within the limits of the general category--from a. list of twelve possible topics, given to them by me. During their talking I want you not to respond.verbally. Listen carefully, but say nothing. They will do all the talking.

At this point, any questions the subjects had were answered. They were then asked to sign a release statement which appears in Appendix A. 
Prior to each subject's entrance to the laboratory,. the physiograph was warmed up, all connections checked, all electrodes cleaned. After the subject signed the release form, he was seated in a chair facing away from the physiograph. He was then "hooked up" to the machine.

The GSR electrodes were placed on the index and middle fingers. The EMG electrodes were attached to the upper trapezius muscle in the following standardized form (Lippold 1967).

Placement of the first electrode was accomplished by drawing a horizontal line running through the area between the spines of the first thoracic and the seventh cervical vertabrae. Then, a mark at the point $1-5 / 8$ inches outward from the midline for placement of the certer of the first electrode was made. This area was covered liberally with electrode paste which was massaged into the skin for approximately 20 seconds. The electrode paste was also spread over the surface of the electrode which was to maintain contact with the skin.

Placement of the second electrode was accomplished by drawing a horizontal line through the space between the spines of the second and third thoracic vertabrae to the posterior edge of the head of the humerus. The center of the second electrode was placed on the point which lies middistance between the backbone and the posterior edge of the head of the humerus. Electrode paste was once more applied 
to the skin and to the surface of the second electrode. A. ground electrode was placed on each subject's forearm to prevent any extra-electrical activity of the body from showing up on the physiograph readout.

After electrode placement, the subject was told:

Find a comfortable position, relax. When the first person comes in and starts, I want you to as much as possible avoid movement of hand, arms, or upper body. It is essential that you stay as still as possible so as not to confound the EMG and GSR data. Remember to listen carefully, but do not respond. They will do all the talking.

The experimenter went outside the laboratory and returned with the first of the three confederates all of whom had been waiting in another room. The experimenter introduced the subject and confederate and then addressed the confederate by name.

now.sit in this chair [opposite the subject], and read to him from Chapter One of this book while I get a baseline. When I wave my hand, you will stop reading, and begin talking about the topic that you chose... O.K., you can begin reading.

The above subterfuge was employed with the hope that the subject would think that the confederate was actually another subject from a different speech class.

Upon signal, the confederate stopped reading and began with the stimulus statement. All confederates had rehearsed their disclosures sufficiently so that each took very close to 1 ininute on each occasion. When the confederate finished, he was thanked and dismissed. The subject was told that he 
could now stretch his muscles and move if he needed to for he would have to remain still when the next person began. The above procedure was repeated three times for each subject, once for each level of disclosure.

When the third confederate had left, the electrodes were removed. The experimenter then said:

O.K. I would now ask you one more thing. Here is a list of the three people you talked to. The names are in order. Which one would you now prefer to continue exploring the topic that they introduced to you here---that is in the context where you can talk about that topic with them, and in another room where I would not be present?

After he made a choice, the subject was told:

It is possible that that person is now busy in another part of this study. If so, do you have a second choice?

In this way, a rank order of preference (attitudinal response) was obtained.

The experimenter made a final statement to the subject:

O.K. Actually, you do not have to talk with anyone. I was only getting an order of preference from you. Now, if you have any questions, I will answer them.

The last request I would make is that you do not discuss what happened here with anyone in your Speech class or anywhere else. It is important that they know nothing of the experiment beforehand. If they ask, just say that it is important to the experiment that people know nothing of the topic.

Thanks very much for coming. 
CHAPTER III

\section{RESULTS}

The results of the study will be presented in order of the three hypotheses and their corresponding measures: electromyographic, psychogalvanic, and attitudinal response. All parametric statistic operations (a three-way-analysis of variance, an orthogonal comparison, and a trend analysis) were performed according to B. J. Winer (1962) in Statistical Principles in Experimental Design. A Wilcoxson matched-pairssigned ranks test followed G. A. Ferguson (1959) in Statistical Analysis in Psychology and Education.

\section{ELECTROMYOGRAPHIC RESPONSE}

Hypothesis 1. Change of electromyographic response will be a linear function of the increasing - intimacy of the stimulus statement.

Response scores were measured in millivolts and obtained by subtracting the subject's baseline from his peak score--as suggested by Malmo (1959). The scores were placed into a three-way analysis of variance, as presented by B. J. Winer (1962). This procedure was completed in order to assezs the significance of main effects and their interactions (see Table III). In the table, "A" represents topic, "B" 
represents sex, and "C" represerts the treatment (disclo-. sure).

\section{TABIE III}

SUMMARY OF ANATYSIS OF VARIANCE; OF EMG

\begin{tabular}{|c|c|c|c|c|}
\hline Source & ss & $d f$ & $\mathrm{~ms}$ & $F^{\prime}$ \\
\hline Between $S$ s & 16.70 & $\underline{23}$ & & \\
\hline A (Topic) & .15 & 1 & .15 & .19 \\
\hline$B(\operatorname{Sex})$ & .48 & 1 & .48 & .63 \\
\hline $\mathrm{AB}$ & .81 & $I$ & .81 & 1.06 \\
\hline $\begin{array}{l}\text { Subject within } \\
\text { groups (error } \\
\text { [between]) }\end{array}$ & 15.26 & 20 & .76 & \\
\hline Within Ss & 2.41 & $\underline{48}$ & & \\
\hline C (Disclosure) & 1.82 & 2 & .91 & $7.0^{*}$ \\
\hline $\mathrm{AC}$ & .03 & 2 & .01 & .07 \\
\hline $\mathrm{BC}$ & .29 & 2 & .14 & 1.07 \\
\hline $\mathrm{ABC}$ & .06 & 2 & .03 & .23 \\
\hline $\begin{array}{l}\text { C X subject } \\
\text { within groups } \\
\text { (error [within]) }\end{array}$ & 5.21 & 40 & .13 & \\
\hline
\end{tabular}

${ }^{*} \mathrm{p}<.01$

As was shown in Table III:

1. Effects of topic (A) were not significant.

2. Effects of $\operatorname{sex}(B)$ were not significant. 
3. There were no significant interaction effects, taken either two at a time, or in the three-way combination.

4. The effect of the independent variable, disclosure (C), was significant $(F=7.0 ; p<.01$ at $d f=2,40$ ) for EMG response; i.e., there was significant variability among $\mathrm{H}, \mathrm{M}$, and $\mathrm{I}$ conditions.

Next an orthogonal comparison of pairs of treatment differences was performed on the EMG data, utilizing total. scores for the three disclosure treatments. See Table IV.

\section{TABLE IV}

ORTHOGONAL COMPARISON OF TOTAL EMG SCORES

\begin{tabular}{ccc}
\hline (Low $)$ & $\mathrm{C}$ (Moderate) & $\mathrm{C}$ (High) \\
\hline 5.99 & 11.53 & 15.28 \\
\hline
\end{tabular}

The comparison between the low and moderate treatment differences was significant $(F=4.84 ; p<.05$ at af $=1,40)$. However, $F$ was not statistically significant when comparing the moderate and high groups $(F=2.23 ; \mathrm{p}>.05$ at $\mathrm{df}=1$, 40).

Finally, a trend analysis was carried out on the above totals in Table IV. As illustrated in Table $V$, the test for 
a linear trend was statistically significant $(F=13.76$;

$p<.01$ at df $=1,40$ ), while the test for a quadratic trend was not significant $(F=1.53 ; \mathrm{p}>.05$ at $\mathrm{df}=1$, 40).

\section{TABLE V}

TREND ANALYSIS FOR EMG

\begin{tabular}{lcccc}
\hline Source & ss & df & ms & $F$ \\
\hline Linear & 1.79 & 1 & 1.79 & $13.76^{*}$ \\
Quadratic & .2 & 1 & .2 & $1.53^{* *}$ \\
Within trials & 5.21 & 40 & .13 & \\
\hline
\end{tabular}

$$
\begin{array}{ll}
{ }^{*} p<.01 \\
{ }^{*} \text { N.S. } & \mathrm{p}>.05 \\
. & \text { II. PSYCHOGALVANIC RESPONSE }
\end{array}
$$

Hypothesis 2. Change of psychogalvanic response will be a linear function of the increasing intimacy of the stimulus statement.

Response scores were measured in "GSR units" as indicated by the rectilinear write-out coordinates on the physiograph paper. Scores were again obtained by subtracting baseline f'rom peak score. In order to assess the significance of main effects and their interactions, the same operations used for the EMG data were employed in analyzing 
the psychogalvanic response to low, moderate, and high selfdisclosure.

Table VI shows the summary of analysis of variance for the GSR. As seen in the table:

1. Effects of topic (A) were not significant.

2. Effects of $\operatorname{sex}(B)$ were not significant.

3. There were no significant interaction effects, taken either two at a time, or in the three-way combination.

4. The effect of the independent variable, disclosure (C), was significant $(F=16.38 ; p>.01$ at $d f=2,40$ ) for GSR response; i.e., there was significant variability among $H, M$, and $I$ conditions. 
TABLE VI

SUMMARY OF ANALYSIS CF VARIAINCE FOR GSR

Source

SS

$d f$

$\mathrm{ms}$

F

Between Ss

162.25

$\underline{23}$

A (Topic)

.17

1

.17

.02

$B(\operatorname{Sex})$

11.28

1

11.28

1.49

$A B$

.01

1

.01

.001

Subject within

groups (error.

[between])

151.29

20

7.56

Within SS

123.17

4.8

C (Disclosure)

53.43

2

26.71

$16.38^{*}$

AC

0

2

0

0

BC

2.68

2

1.34

.82

$\mathrm{ABC}$

1.72

2

.86

.52

C X subject

within groups

(error [within])

\subsection{4}

40

1.63

$* p<.01$

An orthogonal comparison of pairs of treatment differences was also performed on the GSR data, utilizing total scores for the three disclosure treatments (see Table VII). The comparison between the low and moderate treatment differences was significant $(F=6.18 ; p<.01$ at $\mathrm{df}=1,40)$ 
as was the comparison of moderate anō high totals $(F=10.38$; $p<.01$ at $d f=1,40$ ).

\section{TABIE VII}

ORTHOGONAI COMPARISON OF TOTAI GSR SCORES
C (Low)
C (Moderate
C (High)

$$
44.0
$$

66.0

94.5

The last step was a trend analysis carried out on the above totals listed in Table VII. Table VIII shows the results of the tests for both linear and quadratic trends. The test for a linear trend was significant $(F=32.59$; $p<.005$ at $d f=1,40)$. The test for a quadratic trend yielded. an $F<I$, not statistically significant.

TABLE VIII

TREND ANAIYSIS FOR GSR

\begin{tabular}{lrrrr}
\hline Source & ss & df & ms & F \\
\hline Linear & 53.13 & 1 & 53.13 & $32.59^{*}$ \\
Quadratic & .29 & 1 & .29 & $<1^{* *}$ \\
Within trials & 65.34 & 40 & 1.63 & \\
\hline
\end{tabular}

${ }^{*} \mathrm{p}<.005$

$* *$ N.S. 
These trend analyses confirmed the hypothesis that psychogalvanic response is a linear function of increasing levels of intimacy in self-disclosure.

\section{ATTITUDINAL RESPONSE}

The third and last hypothesis stated that attitudinal response will be curvilinear; i.e., it was predicted that subjects would choose to continue interacting with the moderate discloser more often than they choose the high or low discloser for continued interaction.

A rank order of choice of confederate was obtained at the end of the experimental procedure in the manner described in Chapter II. The results of each subject's ranking appear in Appendix B. Table IX shows confederate (H, $\mathbb{M}$, and I) ranking totals. It should be noted that the last subject stated that he did not want to continue interaction with any of the confederates, and that the experimenter entered tied ranks of two (2) for the $I, M$, and $H$ confederates in his case. 
MABIEE IX

SUMMARY OF WILCOXSON T RANKING TOTALS

Confederate Disclosure Level

\begin{tabular}{lrcc} 
Choice & Low & Moderate & High \\
\hline Ist & 3 & 15 & 5 \\
2nd & 11 & 7 & 8 \\
3rd & 10 & 2 & 11 \\
\hline
\end{tabular}

In order to test the hypothesis, a Wilcoxson matchedpairs-signed ranks test (Wilcoxson $T$ ) as presented by Ferguson (1959), was performed on the rank order data. Critical value of $\mathrm{T}$ for the pairing of low and moderate confederates was 45.50 , significant at the .005 level. When moderate and high confederate choices were paired, the critical value of $T$ was 53.50 , also significant at the .005 level.

The hypothesis then, was strongly supported.

\section{ADDITIONAL DATA ANALYSIS}

Barna (1970) stated that reviewers of work on the physiological measurement of tension and anxiety are in agreement as to the lack of substantial correlation among tension-anxiety indicators. Not withstanding this proposition, 
a measure of association was computed for EMG and GSR to . low, moderate, and high self-disclosure.

Response scores were obtained from five 5-secondintervals at $10,20,30,40$, and 50 seconds. In order to assess the degree of correlation in shorter time intervals, scores representing each interval were obtained by summing the deviation from baseline at five discreet points within the interval--as suggested by the rectilinear write-out, coordinates.

Response scores of seven subjects (chosen at random) were placed into a Pearson $r$. Significant $t$ values $(t<.05)$ were obtained for only two--indicating a lack of correlation for five of the seven subjects and thereby terminating the analysis. 
CHAPTER IV

DISCUSSION

The findings confirm all three hypotheses. Electromyographic and psychogalvanic response to low, moderate, and high self-disciosure from opposite-sexed strangers was linear; the greater the intimacy of disclosure, the greater the physiological response. Attitudinal response was curvilinear. Subjects chose the moderate disclosing confederate significantly more often than the high or low discJoser. Sex and topic were controlled, yet made no difference. An analysis of these results follows.

The previously mentioned Barna-Duffian anal.ysis (Chapter I) of physiological measurement of activation suggests that activation is pleasant to a particular point of intensity, after which an organism's witharawal indicates the subjective feeling of apprehension that we call "anxiety." The electromyograph and psychogalvanometer are devices that measure muscle tension and electrical skin resistance, both forms of activation. In this study, activation increased with increasing intimacy of disclosure. And, we can say that the great majority of subjects "approached" the moderate discloser, and "withdrew" from the high and low disclosers-- 
as indicated by the rank order of confederate choice (see Table IX in Chapter III).

These results lend support to Barna's and Duffy's analysis. An application of their analysis might read as follows: the moderate disclosing confederates evoked enough activation to sufficiently excite or challenge the subjects to prefer them for continued interaction to either the high or low disclosing confederates. It might be that the low disclosing confederates bored the subjects through not enough activation; the high disclosers being too jntimate for selection. Subject withdrawal from the high disclosers suggests that the personal nature of the stimulus material caused "anxiety" among the majority of subjects. This lends partial credence to Cozby's (1972) notion that high disclosing others arouse sufficient anxiety for the relationship between liking and intimacy of disclosure to be curvilinear (see Chapter II).

The results also have implications for interpersonal relationship satisfaction. Those having difficulty in effectively engaging others in the initial encounter may be disclosing information that is either overly intimate, or not intimate enough. This study shows that moderately intimate disclosure is received best. 


\section{Iimitations of the Study}

As with all investigations in contrived laboratory settings, there are limits to the generalizability of the results. For example, there are few times when we will confront strangers who will talk to us for one minute only, while we are connected to a physiograph, not allowed to respond verbally or nonverbally. Yet, there are an untold number of variables affecting the initial interpersonal encounter which are beyond the investigator's control in a given study. A barroom setting would differ from a PTA meeting, and these would differ markedly f:rom the counseling office where intimate self-disclosure might be considered a norm. Not only does setting make a difference, but the goals both members of the heterosexual dyad have for the potential relationship would affect the kind and amount of self-disclosure appropriate to the encounter. For example, if one is only seeking sympathy, highly intimate selfdisclosure may be necessary to achieve the desired outcome. However, this study's findings suggest that if one's goals include continued interaction, then highly intimate selfdisclosure upon first meeting may not be an effective strategy. Sétting and goals are only two of the many variables to consider.

Another limitation is the inter-subject variability involved in the experimenter's placement of the EMIG electrodes. 
This may also account for the statistically nonsignificant F when comparing moderate and high ENG orthogonal totals.

\section{Suggestions for Future Research}

Timing of self-disclosure seems to be a crucial variable when the information is of an intimate nature. Selfdisclosure at different stages of relationship affect different people in different ways. Given the results of this study, questions that arise include: exactly when, or at what stage of relationship is it appropriate to engage in highly intimate self-disclosure? Can we distinguish which people will receive intimate self-disclosure early in a relationship better than others? What can we look for in another's appearance, communication, personality characteristics to give us clues to these questions? Answers to these questions might minimize the risks a communicator faces when disclosing highly personal information.

A problem apparent in the theoretical. and empirical literature on self-disclosure is a conceptual fuzziness surrounding the disclosure concept itself. Jourard's definition is "the act of revealing personal information to "others" (Jourard 1971).. This is the one most often used and therefore has been employed in this study. However, it is vague and does not discriminate from certain nondisclosure phenomena such as the way we dress, certain gestures, and the like. 
Other writers have offered alternatives. For example, Culbert defines self-disclosure in this way:

Self-disclosure refers to an individual's explicitly communicating to one or more others some personal information that he believes these others would be unlikely to acquire unless he himself discloses it. Moreover, this information must be "personally private"; that is, it must be of such a nature that it is not something the individual would disclose to everyone who might inquire about it. (in

Miller \& Steinberg 1975)

This definition seems sound to this writer, though some might find it too restrictive--that it eliminates disclosure low in intimacy value. There is still a need for work in the area of definition.

Future investigations should also include research into the effects of different levels of disclosure in specific communication contexts such as the job interview, classroom teaching, and public address situations. Other investigations might look at optimal disclosure levels in small groups with different tasks, goals, and social concerns. Communication context has been, beretofore, a relatively neglected variable.

\section{Summary}

The results of the study confirmed all three hypotheses: 1. Change of electromyographic response was a linear function of the intimacy of the stimulus statement. Electromyographic response increased with increasing levels of disclosure. 
2. Change of psychogalvanic responses was a linear function of the intimacy of the stimulus statement. Psychogalvanic response increased with increasing levels of disclosure. 3. Attitudinal resporse was curvilinear. Subjects chose to continue interaction with the medium discloser significantly more often than they chose either the high or low discloser.

The linear physiological and curvilinear attitudinal responses suggest that Barna and Duffy were correct in theorizing that increasing activation is pleasant to a particular point of intensity after which the state of anxiety is reached.

To the extent that the results are generalizable, this investigation demonstrates that highly intimate or nonintimate self-disclosure early in an initial heterosexual encounter is not as effective for facilitating continued interaction as is moderately intimate self-disclosure. 
REFERENCES CITED

Altman, I., and Haythorn, W. W. 1965. "Interpersonal exchange in isolation," Sociometry, 28: 411-426.

and Taylor, D. A. 1973. Social penetration: The development of interpersonal relationship. New York: Holt, Rinehart \& Winston.

Bach, G. R., and Deutsch, R. M. 1970. Pairing. New York: Avon Books.

Barna, I. M. 1970. "Effects of systematic relaxation training," M.A. thesis, Portland State University.

Benedict, B. A. 1971. "The effects of self-disclosure on the development of trust," Dissertation Abstracts International, 31: (9-B), 5601.

Bernard, J. 1968. The sex game. New York: Atheneum.

Berscheid, E., and Walster, E. H. 1969. Interpersonal attraction. Reading: Addison-Wesley Publishing Co., Inc.

Certner, B. C. 1971. "The exchange of self-disclosure in same sexed and heterosexual groups of strangers," Dissertation Abstracts International, 31: (9-A), 4885.

Chittick, E. V., and Himmelstein, P. 1967) "The manipulation of self-disclosure," Journal of Psychologiy, 65: $117-121$.

Cozby, P. C. 1972. "Self-disclosure, reciprocity, and liking, " Sociometry, 35: 151-160.

1973. "Delf-disclosure: A literature review," Psychological Bulletin, 79: 73-91.

Dimond, R. E., and Munz, D. C. 1967. "Ordinal position of birth and self-disclosure in high school students," Psychological Reports, 21 : 829-833.

Duffy, E. 1962. Activation and behavior. New York: John Wiley and Sons, Inc. 
Ehrlich, H. J., and Raeven, D. B. 1971. "Reciprocal selfdisclosure in a dyad," Journal of Experimental Social Psychology, 7: 389-400.

Fast, J. 1971. The incompatibility of men and women. New York: Avon Books.

Ferguson, G. A. 1959. Statistical analysis in psychology and education. New York: McGraw-Hill Book Co., Inc.

Fitzgerald, M. P. 1963. "Self-disclosure anả expressed self-esteem, social distance, and areas of the self revealed," Journal of Psychology, 56: 405-412.

Gilbert, S. J. 1973. "A study of the effects of selfdisclosure on interpersonal attraction and trust as a function of stiuational appropriateness and the selfesteem of the recipient, "Dissertation Abstracts International, 33: (8-A), 4566-7.

Halverson, C. F. Ir., and Shore, R. E. 1969. "Selfdisclosure and interpersonal functioning," Journal of Consulting and Clinical Psychology, 33: $21 \overline{3}-217$.

Homans, G. C. 1961. Social behavior: Its elementary forms. New York: Harcourt, Brace \& World, Inc.

Hood, T. C., and Back, K. W. 1971. "Self-disclosure and the volunteer; A source of bias in the laboratory," Journal of Personality and Social Psychology, 17: $130-136$.

Jones, E. E., and Gordon, E. M. 1972. "Timing of selfdisclosure and its effect on personal attraction," Journal of Personality and Social Psychology, 24: $358-365$.

Jourard, S. M. 1959. "Healthy personality and selfdisclosure," Mental Hygiene, 43: 499-507. (a)

1959. "Self-disclosure and other-cathexis," Journal of Abnormal and Social Psychology, 59: 428-

1961. "Age trends in self-disclosure," Merrill-Palmer Quarterly, 7: 191-197.

1964. The transparent self. Princeton: Van Nostrand. 
1971. Self-disclosure: An experimental analysis of the transparent self. New York: WileyInterscience.

and Friedman, R. "Experimenter-subject 'distance' and self-disclosure, "Journal of Personality and Social Psychology, 15: $278-282$.

and Landsman, M. J. 1960. "Cognition, cathexis, and the 'dyadic effect' in men's self-risclosing behavior," Merrill-Palmer Quarterly, 6: 178-186.

, and Lasakow, P. 1958. "Some factors in selfdisclosure," Journal of Abnormal and Social Psycholog:y, 56: 91-98.

, and Richman, P. 1963. "Disclosure output and input in college students, " Merrill-Palmer Quarterly, 9: 141-148.

Levin, F. M., and Gergen, K. J. 1969. "Revealingness, ingratiation, and the disclosure of self," Proceedings of the 27th Annual Convention of the American Psychological Association, 4 (pt 1): 447-448.

Levinger, G. and Senn, D. J. 1967. "Disclosure of feelings in marriage," Merril1-Palmer Quarterly, 13: 237-249.

Levitt, E. E. 1967. The psychology of anxiety. Indianapolis: The Bobbs-Merrili Co., Inc.

Lippold, O. C. 1967. "Electromyography," in A manual of psychophysical methods. Edited by P. H. Venables and I. Martin. Ansterdam, Holland: North Holland Publishing Company.

Malmo, R. B.. 1959. "Activation: A neurophysiological dimension," Psychological Review, 66: 367-386.

Mead, G. H. 1934. Mind, self, and society. Chicago: The University of Chicago Press.

Miller, G. R.; and Steinberg, M. 1975. Between people: A new analysis of interpersonal communication. Palo Alto: Science Research Associates, Inc.

Phillips, G. M. 1973. "Prologue to an interpersonal rhetoric," Pennsylvania State University. 
and Metzger, N. J. 1976. Intimate communication. Boston: Allyn and Bacon, Inc.

Plog, S. C. 1965. "The disclosure of self in the United States and Germany, "Journal of Social Psychology, 65: $193-203$.

Polansky, N. A. 1967. "On duplicity in the interview," American Journal of Orthopsychiatry, 37: 568-580.

Rickers-Ovsiankina, M. A. 1956. "Social accessibility in three age groups," Psychological Reports, 4: 391-406.

Rivenbark, W. H., III. 1971. "Self-disclosure patterns among adolescents," Psychological Reports, 28 : 35-42.

Rogers, C. R. 1961. On becoming a person. Boston: Houghton Mifflin.

Spielberger, C. D., ed. 1966. Anxiety and behavior. New York: Academic Press.

Taylor, D. A. 1968. "The development of interpersonal relationships: Social penetration processes," Journal of Social Psycholozy, 75: 79-90.

and Altman, I. 1966. "Intimacy-scaled stimuli for use in studies of interpersonal relations," Psychological Reports, 19: 729-730.

$\therefore$ Altman, I., and Sorrentino, R. 1969. "Interpersonal exchange as a function of rewards and costs and situational factors: Expectancy confirmationdisconfirmation, " Journal of Experimental Social Psychology, 5: $324-339$.

Thibaut, J.W:, and Kelly, H. H. 1959. The social psychology of groups. New York: Wiley.

Truax, C. B., and Carkhuff, R. R. 1965. "Client and therapist transparency in the psychotherapeutic encounter, " Journal of Counseling Psychology, 12: $3-9$.

Vondracek, S. I., and Vondracek, F. W. 1971. "The manipulation and measurement of self-disclosure in preadolescents," Merrill-Palmer Quarterly, i7: 51-58.

West, L., and Zingle, H. W. 1969. "A self-disclosure inventory for adolescents, " Psychological Reports, 24: $439-445$. 
Winer, B. J. 1962. Statistical principles in experimental design. New York: McGraw-Hili Book Co., Inc.

Worthy, M. , Gary, A. I., and Kahn, G. M. 1969. "Selfdisclosure as an exchange process, "Journal of Personality and Social Psychology, 13: 59-63. 
APPENDIX A

RELEASE STATEMENT 
RELEASE STATEYENT

I, wish to state that I have offered myself as a subject tor an empirical study under the sponsorship of the PSU Speech Communication Department. I have not been coerced or forced to participate against my will. I have been informed about the procedures of the study and I understand that any information regarding my participation will be treated confidentially and that publication of such information will conceal my identity.

Date Signature

ID\#

Class standing Fr Soph. Jr Sr Sex M F Age 


\section{APPENDIX B}

\section{SUBJECT RANKING OF CONFEDERATES}


SUBJECT RANKING OF CONHEDERATES

Subject

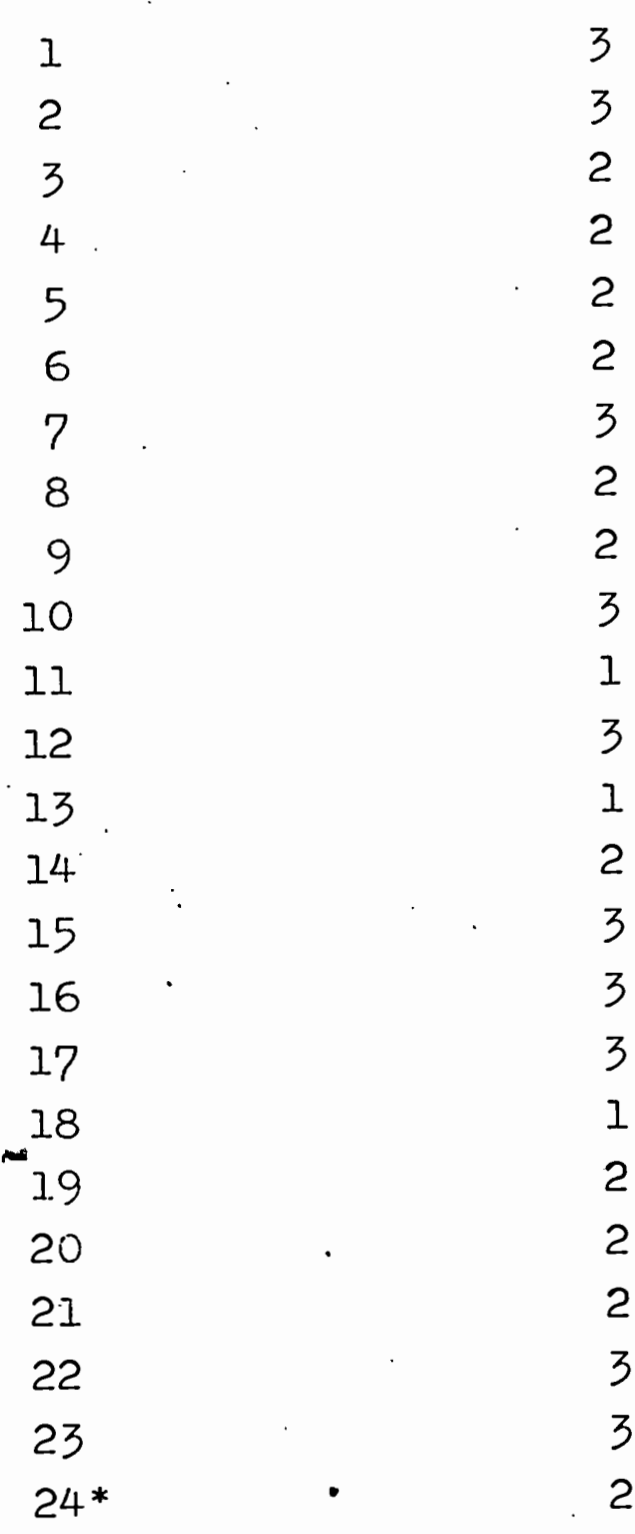

Rank order of choice of confederates Low Moderate High

32 I

1

3

1

1

$I$

2

1

1

2

3

2

2

I

1

1

1

2

1

1

I

1

1

2
1

2

1

3

3

3

1

3

3

1

2

1

3

3

2

2

2

3

3

3

3

2

2

2

*Experimenter entered tied ranks 